Aletria, Belo Horizonte, v. 29, n. 3, p. 61-77, 2019

\title{
Um teórico na pós-modernidade
}

\section{A Theorist in Post-Modernity}

\author{
Thiago Castañon Loureiro \\ Universidade Federal do Rio de Janeiro (UFRJ), Rio de Janeiro, Rio de Janeiro / Brasil \\ thiagocastanonloureiro@gmail.com
}

Resumo: Em homenagem aos cem anos da teoria da literatura (1917-2017), que coincide com os 80 anos de Luiz Costa Lima, o presente artigo propõe fazer um balanço do lugar que a obra do pensador brasileiro ocupa no cenário atual, contextualizando sua contribuição no que pode ser considerado o terceiro momento (pós-moderno) de problematização da literatura. Partindo do nascimento da ideia de uma teoria da literatura com Schlegel, verifica-se o adiamento desse começo até as primeiras décadas do século XX. Será a partir dos anos 1980, quando se propaga a crise da "alta teoria" da literatura, que Costa Lima se destacará por deslocar sua questão fundamental (o que é literatura?) do marco antropológico do sujeito kantiano, pela reindagação da mímesis, apontando novos problemas para a reflexão contemporânea sobre o poético.

Palavras-chave: Luiz Costa Lima; teoria da literatura; mímesis; sujeito; pósmodernidade.

Abstract: In honor of the 100th anniversary of literary theory (1917-2017), which
coincides with Luiz Costa Lima's 80th birthday, the present article proposes to analyze
the place occupied, in the current scenario, by the Brazilian thinker. It will be done
by contextualizing Lima's contributions, which can be perceived as part of the third
moment (postmodern) of literature problematization. It is verified that the development
of Schlegel's conception of literary theory was delayed until the first decades of the
20th century. It is in the 1980s, when the crisis of "literary high theory" spreads, that
Costa Lima stands out by displaying its fundamental question (what is literature?), based
on the anthropological framework of the Kantian subject. Such analysis is performed
by the inquiry of mimesis, and by highlighting new problems to the contemporary
reflection on the poetic.

Keywords: Luiz Costa Lima; literary theory; mímesis; subject; postmodernity.

eISSN: 2317-2096

DOI: $10.17851 / 2317-2096.29 .3 .61-77$ 
A fim de analisar alguns aspectos da obra de Luiz Costa Lima e sua posição na história recente da teoria literária, começo por um breve resumo da formação da teoria da literatura como disciplina específica, seguida da constituição da literatura como pergunta a que aquela propõe responder, para vir ao modo como o autor propõe retomar sua discussão. Com surgimento simultâneo no primeiro romantismo alemão, estas duas paralelas serão partilhadas, por sua vez, em três momentos distintos de problematização da literatura, que procuramos caracterizar a seguir como modernidade, alto modernismo e cena atual pós-moderna.

Embora tenha sido cunhada por Friedrich Schlegel na "Introdução" ao curso de História da literatura europeia, oferecido por ele em 18031804, a expressão "teoria da literatura" não volta a ser utilizada por seu autor. O início de reflexão teórica nascido com seus fragmentos também será rapidamente abafado pelas cadeiras de história da literatura então criadas nas diversas universidades europeias, a partir de um interesse político: promover a ideia de nacionalismo. Sintomaticamente, seu próprio iniciador seria o primeiro a abandonar a teoria em favor da história da literatura. Como se lê logo nas primeiras páginas da Einleitung (cito a tradução de Costa Lima):

Antes de começarmos nossa exposição histórica será necessário oferecer um conceito provisório de literatura, que precise a dimensão e os limites do todo. Mas esse conceito só pode ser provisório na medida em que o conceito mais pleno é a própria história da literatura. ${ }^{1}$

Conquanto seja necessário um conceito preliminar "que precise a dimensão e os limites do todo", a fim de traçar o espaço da sua exposição histórica, à teoria só cabe oferecer uma definição provisória (incompleta), mesmo porque, dirá adiante, ela só pode ser parcial (localizada). O dado intrigante é que Schlegel não se contenta em romper com as estéticas normativas pré-românticas pela ênfase na historicidade intrínseca da obra literária, mas subordina a teorização, que aponta ao mesmo tempo como plausível e necessária, ao "conceito mais pleno" de literatura, que só poderia ser fornecido pela visão de conjunto, da alçada da história da literatura.

${ }^{1}$ SCHLEGEL. Introdução à história da literatura europeia, p.134. 
Donde o conceito provisório da introdução partir do vasto acumulado do tempo. A começar pela acepção mais antiga do termo: "Usualmente toma-se por literatura todas as ciências e artes que agem pela linguagem [in der Sprache wirken]". Nesse sentido, diz Schlegel, a literatura abrange a poesia, a história, a retórica, a moral, a erudição e a filosofia. Estes, por sua vez, divididos em dois gêneros superiores, a ciência e a arte, formando três grupos: gêneros de arte (poesia), gêneros de ciência (filosofia) e gêneros híbridos (retórica, história, etc.). Sendo a poesia e a filosofia as duas formas privilegiadas que estruturam o campo da literatura, esta comporta desde formas que se expressam por imagens até aquelas que empregam conceitos. A filosofia abrangendo todas as ciências que se exprimem por signos, a poesia cobrindo toda a arte, e não somente a que age pela linguagem. Conclusão provisória a ser tirada: "à medida que a literatura abrange todas as ciências e artes, é ela a enciclopédia". ${ }^{2}$

Mas perguntar-se-á: dizê-la "enciclopédica" não equivale a manter a literatura no molde da velha categoria das belas-letras? Então, como se poderá falar em concepção autonômica do literário nesse contexto? À diferença das belas-letras, a nova inscrição da literatura oferecida por Schlegel como "enciclopédia dos saberes humanos" não decorre de uma legitimação pela imitatio, mas da exploração da infinita riqueza interior do eu, como veículo de sua Bildung (formação). Não é outra a razão declarada da indeterminação do termo:

em ambas [poesia e filosofia] o homem é o objeto mais destacado, na verdade, o homem como todo, em sua indivisa unidade, enquanto as outras [ciências e artes] não se detêm na observação do todo e se perdem em partes e finalidades isoladas. Por isso, o estudo da poesia e da filosofia é chamado o estudo das humaniora. Tão logo tomamos a poesia e a filosofia como as mais universais e fazemos entrar as obras existentes, somos cercados pela amplitude da literatura. ${ }^{3}$

Se a literatura é "enciclopédia" que acolhe textos de diversas áreas, é sua própria amplitude que justifica a necessidade de uma reflexão

\footnotetext{
${ }^{2}$ SCHLEGEL. Introdução à história da literatura europeia, p.135.

${ }^{3}$ SCHLEGEL. Introdução à história da literatura europeia, p.139-140, grifo meu.
} 
simultaneamente teórica, e não apenas histórica, pois "para que não nos percamos então neste caos será preciso que tenhamos uma visão de conjunto. Essa visão só pode ser dada histórica e filosoficamente. [...] Pois a literatura [dada sua extensão heterogênea] só é compreensível no todo". ${ }^{4}$

Feita essa contextualização preliminar, vejamos como a expressão "teoria da literatura" faz sua primeira entrada no texto da Geschichte der europäischen Literatur.

Poder-se-ia também indagar se não se deveria privilegiar uma visão de conjunto da literatura através da filosofia, i.e., uma teoria da literatura. É evidente que tal teoria é possível. Todos os gêneros e modos de poesia e filosofia se deixam construir a partir do conhecimento de nossa própria consciência, ou seja, da consciência humana. [...] Tal teoria, contudo, para aquele que operasse sem conhecimento histórico, daria uma visão apenas incompleta da literatura". ${ }^{5}$

Declará-la possível equivale a dizer que o que se chama de teoria da literatura não apenas ainda não existe, mas que não se confunde com a divisão retórica em modelos de imitação praticada pelos antigos. Esta supunha normas de composição e avaliação, enquanto a teoria dos modernos, concebida por Schlegel como "divisão filosófica da poesia em gêneros e modos", terá como pressuposto o conhecimento da "consciência humana" por si mesma. Se a reflexão teórica passível de ser criada se faz ademais necessária para a crítica, visto que "a avaliação das diversas obras literárias [...] não é possível sem conhecimento e diferenciações filosóficas", ${ }^{6}$ ela será apenas parcial se não for acompanhada pelo conhecimento histórico. Este, por sua vez, "pode conter em si o filosófico, pois não prejudica a exposição [Darstellung] [...] se se examina filosoficamente a representação histórica". ${ }^{7}$ Assim, a história da literatura se sobrepõe à teoria da literatura à medida que não apenas a complementa, mas a precede e designa seu lugar:

\footnotetext{
${ }^{4}$ SCHLEGEL. Introdução à história da literatura europeia, p. 140.

${ }^{5}$ SCHLEGEL. Introdução à história da literatura europeia, p.140, grifo meu.

${ }^{6}$ SCHLEGEL. Introdução à história da literatura europeia, p.143.

${ }^{7}$ SCHLEGEL. Introdução à história da literatura europeia, p.141.
} 
Já a ordenação cronológica, a divisão em épocas e tempos, a que o método histórico dá lugar, oferece o espaço filosófico. Por cada período, permite-nos [...] levar em conta a divisão filosófica segundo gêneros e modos, a teoria da literatura. Assim então nossa visão de conjunto da literatura se torna uma visão característica, quanto às nações, autores e obras, uma visão cronológica, quanto ao espírito da literatura no curso das épocas e uma visão geográfica, de certo modo quanto ao fundamento, quanto à teoria das diversas formas e gêneros da poesia e da filosofia, que até certo ponto, é uma escala do espírito humano, que certamente assinala a cada um seu lugar no grande império da consciência. ${ }^{8}$

Como explicita a segunda (e última) ocorrência da expressão "teoria da literatura" em Schlegel, se o conceito mais pleno de literatura só pode ser dado pela história da literatura, i.e., pela visão de conjunto que deve englobar a crítica, a história e a teoria - numa visão característica, cronológica e geográfica - a reflexão filosófica da poesia decorre de uma base antropológica meta-histórica que assinala à teoria da literatura o seu lugar no "grande império da consciência". Portanto, se poesia é o termo específico, referente a uma esfera autônoma (ela é a arte das artes), o termo literatura efetua um duplo compromisso com a antiga concepção de belas-letras (ela é enciclopédia) e com a concepção própria do romantismo: sua legitimação pela Bildung, como expressão do infinito interior do espírito, que encontra seu ponto mais alto na história das literaturas nacionais.

Como conjunto formado por "poesia" e "filosofia", a literatura se distingue por ter por objeto "o homem como um todo, em sua indivisa unidade", enquanto as chamadas humanidades apenas o obtêm em parcelas. Portanto, a literatura é o que unifica o espaço fragmentado dos saberes na modernidade pós-kantiana na forma de um conjunto heterogêneo cuja amplitude expressa a "indivisa unidade" do sujeito.

Ao lado do privilégio institucional das histórias das literaturas nacionais, a especialização da crítica científica como ciências históricas no século XIX vai ocupar-se basicamente com sua função prática de mediação, empenhando-se no resgate do sentido "verdadeiro" do texto. Sem desenvolver uma teorização própria sobre a diferença do objeto

${ }^{8}$ SCHLEGEL. Introdução à história da literatura europeia, p.142-143, grifo meu. 
literário, ela toma de empréstimo a outras ciências (filologia, psicologia e sociologia) seus métodos e conceitos, limitando-se a aplicá-los a seu material, convertendo a obra literária em ilustração de uma linha de pensamento ou de um momento histórico previamente estabelecidos.

Assim como a distinção também feita por Schlegel entre "crítico" e "juiz de arte" tampouco encontra eco antes de se tornar objeto de tese doutorado escrita pelo jovem Walter Benjamin em 1919; do mesmo modo que as reflexões teóricas esboçadas pelo autor dos Fragmentos críticos e dos Fragmentos do Ateneu, desprezadas pelo privilégio da história da literatura; de sua ideia de uma teoria da literatura possível restam apenas os breves lampejos contidos na Einleitung, que não terão melhor destino. Mesmo porque não tinha força suficiente para se contrapor ao argumento afinal vitorioso com o prestígio esmagador do hegelianismo. Como observa seu tradutor:

A intuição - e Schlegel é o autor de intuições fantásticas que deixava em estado de fragmentos - de uma teoria da literatura - suponho tenha sido ele o primeiro a empregar a expressão -, que, ressaltando o lastro filosófico, ajudaria a romper a disputa, não foi levada adiante. Ao contrário será preciso que o esforço teorizante se afirme para que, retrospectivamente, os ensaios de Schlegel assumam sua merecida relevância. ${ }^{9}$

Somente no século seguinte a expressão "teoria da literatura" voltará a ser empregada. Pouco antes da fundação do círculo linguístico de Moscou, ela reaparece com Alexander Portebniá nas suas "Notas para uma teoria da literatura" (1905), livro que será alvo de debate no artigo de Viktor Chklóvski, "A arte como procedimento" (1917), considerado um "manifesto teórico" da OPOIAZ (Sociedade para o estudo da linguagem poética). Na sequência, a expressão "teoria da literatura" se reencontra em Boris Tomachevski (1925), migrando depois para Praga e daí para os Estados Unidos, tornando-se termo corrente com a publicação do manual homônimo de René Wellek e Austin Warren, em 1942.

Como assinala a lenta difusão do nome da disciplina, a reflexão teórica apenas começa a se estabelecer nas três primeiras décadas do século XX, a partir de uns poucos nomes isolados, como os que Stálin

${ }^{9}$ SCHLEGEL. Introdução à história da literatura europeia, p.152. 
chamou de formalistas. Destacam-se, então, ao lado desse grupo reduzido de intelectuais russos (que têm sua atuação abreviada pela censura), os nomes de György Lukács, Walter Benjamin, Mikhail Bakhtin, Paul Valéry, Jan Mukarovský e Roman Ingarden, por suas contribuições para o que se chamará a partir de então "teoria da literatura", constituída em "escolas" com métodos próprios de análise literária, que tomam corpo na primeira metade do século XX: formalismo eslavo, new criticism, estilística, análise sociológica, fenomenologia, psicanálise, hermenêutica, entre os métodos mais difundidos.

Tendo-se originado com foco breve, porém privilegiado em Moscou/Petrogrado/Praga, migrando para os Estados Unidos, depois de ser adiada por mais meio século, dessa vez pela eclosão de duas Guerras, a disciplina passa a integrar o quadro universitário no final dos anos 1950. É então, a partir das décadas de 1960 e 1970, que a teoria da literatura encontra condições de se desenvolver sistematicamente. Suas tentativas mais ambiciosas de formular um conceito autonômico de literatura, culminadas no estruturalismo e na estética da recepção, serão, entretanto, logo abandonadas pelo pós-estruturalismo e pela desconstrução, não chegando à década seguinte. No espaço deixado vago pelas grandes "escolas" de teoria literária a partir dos anos 1980, vão se estabelecer os estudos culturais e o pragmatismo, cujo foco de interesse já não está na distinção entre literatura e não-literatura, mas no uso que dela fazem seus leitores. Por ora, observe-se apenas que é nesse momento que Costa Lima começará a publicar seus primeiros ensaios, dando inflexão diversa à crise da teoria. Mas antes de vir a sua resposta, acrescentemos a segunda paralela do quadro.

Passando ao breve relato do problema "o que é literatura?", não teremos em vista a história do concurso de suas definições, mas a da pergunta a que respondem as diversas concepções teóricas elaboradas desde o final do século XVIII, isto é, a colocação da literatura em questão. O esboço dessa história não será muito longo. Não só por começar em data recente, com o romantismo - a partir de sua distinção quanto às belas letras -, mas na medida em que terá sua manutenção abreviada pela chegada do pós-moderno. Dito de outro modo: dada a presença prévia de uma instituição normativa dos gêneros literários, que preservava o leitor da dúvida acerca de sua diferença frente a outros tipos de discurso, a questão "o que é literatura?" não encontra condições de ser formulada antes da modernidade e tampouco sobrevive a sua courte durée. 
Depois de enfraquecida a legitimação das belas-letras pela utilidade - instruir ou deleitar -, até então submetida à legislação da gramática, da retórica e da poética, a nova legitimação da literatura pressupõe a conceitualização da distinção entre razão e sensibilidade. Dentro destes parâmetros estritamente antropológicos, a literatura passa a integrar o domínio dos saberes emergentes na modernidade: inicialmente a jurisdição da estética, no séc. XVIII, como especialidade filosófica; a seguir as jurisdições da história literária, no séc. XIX, como unidade superior de especialidades científicas - biografia, sociologia, filologia circunscrevendo a cultura literária de uma nação; e a jurisdição da crítica literária, como livre exercício do gosto individual. ${ }^{10}$

Distinguindo esse primeiro momento de formação da ideia moderna de literatura, tomemos como seu ponto de partida o final do século XVIII, com a autonomização da experiência estética na terceira crítica de Kant, podendo datar seu limite por volta do final do séc. XIX, com a crise dessa ideia primeira de literatura, que acentuando-se a partir de Baudelaire encontrará um termo em Kafka. O que caracteriza essa etapa é o fato da questão "o que é literatura?" ser colocada, mas não assumida como problema. Dado que seu conceito autonômico se estabelece sobre o marco antropológico de um sujeito autocentrado, enquanto permanecer entendida como "expressão da individualidade" $a$ literatura não será encarada enquanto desprovida de legitimação prévia, ou seja não encontra as condições para se constituir em problema. Apenas quando este paradigma teórico entrar em crise, no final do século XIX, junto com as chamadas "ciências do espírito", a literatura se tornará então objeto de um novo questionamento que não se ocupará da verdade do homem interior, mas da verdade da linguagem poética.

Com início nas primeiras décadas do século $\mathrm{XX}$, o segundo momento do nosso percurso se distingue, então, como resposta à crise da noção moderna de literatura antropologicamente definida. Tomando seus métodos e conceitos de empréstimo das "ciências humanas" recém constituídas, a teoria da literatura vai se alinhar entre estas, impulsionada pela fenomenologia de Husserl e pela linguística de Saussure, visando uma fundamentação da crítica como "ciência da literatura" capaz de fornecer uma nova base de legitimação para a autonomia do poético. A

${ }^{10}$ SOUZA. Uma ideia moderna de literatura: textos seminais para os estudos literários, p.14. 
novidade aqui consiste em que o intercâmbio com as demais ciências humanas é formulado em vista de um problema preciso: constituir uma teoria da literatura dotada de critérios próprios para averiguar a diferença de seu objeto quanto ao das disciplinas com que dialoga. Esta etapa, por sua vez, tem limite assinalável nos anos 1970, com a crise da noção de literariedade e seu abandono pelo pós-estruturalismo. Se quisermos situar dois extremos, podemos dizer que este segundo momento de problematização da literatura se estende, aproximadamente, de Chklóvski a Derrida. Tendo principiado por erigir o ser da literatura no lugar vazio deixado pelo ser do homem, a tentativa de teorização posterior buscará preservar seu caráter indeterminado, restituindo à literatura o status de "terra ignota".

Vindo ao terceiro momento, localizarei seu início no que Lyotard chamou de crise dos "grandes relatos" de legitimação. Limito-me a distinguir a cena pós-moderna, no que concerne a nosso tema, por dois traços mínimos: pelo declínio da teoria (ou, pelo menos, da "alta teoria") da literatura, substituída por um novo gênero que se nomeia simplesmente "teoria", como prática interdisciplinar, sem objeto específico; ou pelo deslocamento de objeto, que se transfere dos "estudos literários" para os "estudos culturais". Nos dois casos, o acordo resultante será o abandono da distinção literatura / não-literatura como tema central da reflexão poética. Nesse sentido será correto tomar a crise da teoria da literatura como um caso particular da desconfiança pós-moderna em relação às grandes narrativas, às grandes sínteses, i.e., os grandes sistemas explicativos que Lyotard chamou de "metarrelatos de legitimação". Se antes do século XX, portanto, a questão "o que é literatura" não constitui problema teórico, depois dos anos 1970, ela deixará de sê-lo para se declarar inominável: distinguindo-se justamente por não caber em nenhuma legitimação prévia. Partindo dessa definição negativa, a terceira etapa se caracterizará pela recusa do conceito autonômico de literatura, senão pela impossibilidade de definir fronteiras para o discurso literário. De modo que, a partir dos anos 1980, a pergunta "o que é literatura?" será afastada de sua função coordenante dos estudos literários, para ter a própria possibilidade de sua teorização colocada sub judice. Como dirá Stanley Fish, exacerbando o novo horizonte da questão: "literatura é aquilo que uma comunidade interpretativa chama de literatura".

O que caracteriza o terceiro momento de problematização da literatura, portanto, como pano de fundo contra o qual se elabora a 
proposta teórica de Costa Lima, será uma retomada literal do limite kantiano: uma vez que a literatura se reduz a uma mera etiqueta institucional, como produto de convenções pragmáticas ou projeção de normas ideológicas, à crítica restará apenas falar de seus efeitos sobre o leitor. Entendida desse modo, a epistemologia pós-moderna constitui um sintoma apenas mais radical da permanência do paradigma do sujeito. Convertendo em norma a transgressão de limites do conceito de literatura, a ausência de parâmetros diferenciados deixa amplo espaço para o árbitro individual exercer sua "livre normatividade". Desse modo, o objeto estético só se legitima, no limite, por sua utilidade prática: seja a mais mesquinha, de ganho de prestígio acadêmico, ou a mais nobre, de contribuição para a luta política. Então a questão que o estudante, o Estado e a instituição de ensino superior dirigem ao pesquisador não será mais: "isto é verdadeiro?", mas passa a ser: “pra que serve?". Pressupondo uma legitimação baseada apenas no aumento de poder: na forma "isto é eficaz?", ou a diretamente respaldada na mercantilização do saber: "isto é vendável?". Em ambos os casos o critério decisivo passa a ser a melhor performance. Que importa se a obra estudada é ou não literatura, ou se possui valor estético, desde que haja um acordo prévio entre o crítico e seu leitor sobre suas respectivas visões de mundo e concepções do objeto literário, em particular?

Assim como as linhas teóricas de seus contemporâneos (pósestruturalismo, desconstrucionismo, marxismo, multiculturalismo, pragmatismo), a obra de Costa Lima começa por questionar a possibilidade de uma efetiva teoria da literatura, pondo em xeque a validade dos metarrelatos de legitimação da literatura moderna. Insistir na possibilidade de extrair, deste contexto de crise, as bases de uma teoria da literatura renovada será sua primeira divergência quanto ao cenário da pós-teoria.

Dos três grandes cortes que assinalamos na história da problematização da literatura, a primeira fase, situada entre Kant e Kafka, é objeto de discussão central por Costa Lima no livro Limites da voz (1993), obra-síntese da primeira etapa de sua produção teórica autoral, iniciada com Mímesis modernidade (1980), que culmina no deslocamento da noção de literatura, por Kafka, em relação ao marco do sujeito kantiano. 
A segunda etapa, que situamos entre o formalismo eslavo e as correntes teóricas dos anos 1960 e 1970, coincide, em seu momento áureo, com o período de formação do jovem Costa Lima. Nessa fase preparatória do salto que propõe, seus textos dialogam sobretudo com o estruturalismo e a estética da recepção, traduzindo, divulgando e desenvolvendo suas premissas. Mas não é apenas com as teorias contemporâneas que seus escritos debatem. Na mesma época, durante os anos 1970, Costa Lima dedica-se a estudar a história da disciplina em que começava a trabalhar, fazendo uma releitura sistemática de seus textos fundadores, do formalismo russo até seu momento atual. É quando principia a reler igualmente a história da estética filosófica, questionando as teorias de Platão, Aristóteles, Kant e Hegel. Ao termo desse percurso, seus “escritos de véspera" sairão inteiramente reformulados, para assumir um perfil autônomo a partir da década seguinte.

Do terceiro momento, por sua vez, sua própria obra será parte, com uma contribuição substantiva para a teoria literária atual. Assumindo uma posição de contrafluxo à chamada pós-modernidade, desde os anos 1970, seus livros vão responder a uma ideia fixa que poderíamos condensar nos termos: "como é possível estabelecer uma (nova) base epistêmica para teoria da literatura?”. Será nos anos 1980, através de uma retomada requestionadora da terceira crítica de Kant, combinada à reformulação da mímesis aristotélica, que Costa Lima vai traçar um espaço próprio para sua teoria literária. Constituída no atravessamento simultâneo com a antropologia e a psicanálise, a teoria da literatura então produzida por Costa Lima se alimentará de contribuições das diversas ciências humanas e das proposições de seus precursores na crítica literária para submetê-las ao tribunal de uma crítica da razão estética, convertendo-as em peças de um "processo" que propõe a refundação da teoria como análise dos limites da literatura.

Supondo que o dito será bastante para caracterizar a posição assumida pela produção do autor, dediquemos umas poucas linhas ao conceito-chave com que Costa Lima propõe formular uma nova base de legitimação para o discurso literário. Embora raramente nos demos conta de sua presença em nossos atos e palavras, segundo o teórico brasileiro, a mímesis seria, sobretudo de forma inconsciente, o veículo pelo qual se processam tanto a constituição da identidade subjetiva, como a inserção do indivíduo em um agrupamento social. Nos termos com que introduz sua discussão: 
Quanto mais nos sentimos integrados em uma cultura, dentro desta, em uma classe, dentro da classe, em uma camada social, dentro desta, em um meio profissional, tanto mais perdemos a possibilidade de saber o que significa esta inserção. A ambiência social nos atravessa como se fosse nossa própria natureza. Cultura, classe, camada meio profissional parecem-se então a roupas muito leves, tão leves que a pele não sente que as transporta. Melhor, roupas que se tornam a própria pele, da qual não nos imaginamos despossuídos. Então julgamos que nossos hábitos, condutas e práticas são nossos simplesmente porque pertencemos à humanidade. Não é que assim esqueçamos nossa personalidade; apenas a hipertrofiamos. ${ }^{11}$

Por aí se vê que, para Costa Lima, a mímesis não se confunde com a experiência da ficção. Se esta, por certo, caracteriza seu produto mais frequente, que se reconhece como obra literária, a mímesis provoca ainda a expansão do próprio termo literatura, ao torná-lo capaz de acolher uma multiplicidade de escritas que se estendem além do ficcional. A essa razão, por si bastante para justificar o desafio que o termo literatura apresenta à tentativa de delimitação de seu campo, acrescenta-se outra, mais arraigada. À medida que ambas partem deste solo comum, nem a literatura, nem a ficção se desgarram do paradoxo que define a atuação da mímesis no tecido social. Donde a hipótese a ser explorada: é mesmo por sua anterioridade à experiência estética que a mímesis constitui a base sobre a qual se afirma tanto a deslegitimação da noção autonômica de literatura quanto a possibilidade de sua teorização.

Sem o propósito de explorar aqui a distinção entre gêneros ficcionais, não-ficcionais e formas híbridas de literatura, pelo modo como realizam diversamente o trabalho da mímesis, limito-me a notar que sua reformulação como "produção de diferença" fornece a Costa Lima, a partir dos anos 1980, uma primeira base para distinguir essa "constelação da literatura", sem cogitar de sua definição substantiva. Ou seja, contemporaneamente ao momento em que a teoria literária pósmoderna renuncia, por obsoleta ou insolúvel, à questão das fronteiras do discurso literário, a retomada da mímesis por Costa Lima apenas esboça sua reabertura.

${ }^{11}$ LIMA. Mímesis e modernidade: formas das sombras, p.85. 
Visando explicitar o deslocamento que decorre da reviravolta proposta sobre a mímesis em relação ao marco antropológico da ideia moderna de literatura, as breves anotações que se seguem acerca de seus modos opostos de realização serão suficientes para verificar, ao mesmo tempo, em que a mímesis cumprida fora da arte contém em si mesma os obstáculos para o reconhecimento de sua diferença artisticamente realizada.

Ao passo que no cotidiano a mímesis tem como resultado mais frequente a naturalização da cultura, a crença de que nossos hábitos, práticas e valores são nossos "simplesmente porque pertencemos à humanidade", na experiência estética, ela pressupõe ao contrário, na célebre expressão de Coleridge, uma "desejada suspensão da descrença" (willing suspension of disibelief). Para dizer de outro modo: se por força de ignorar que a exercemos em nosso comércio diário, terminamos frequentemente confundidos às máscaras de que nos travestimos no contato com o outro (as outras personas), com facilidade se percebe o que distingue a prática dominante da mímesis: por ela não só "esquecemos" que até na mais anódina conversa cotidiana se realiza uma pequena cena teatral ${ }^{12}$, mas acabamos nos persuadindo (e que triste convicção!) de que realmente somos os papéis que representamos - mesmo quando não sabemos que o fazemos, encenando para nós mesmos o papel tragicômico da "alma sincera". ${ }^{13}$

Se a mímesis não se confunde, pois, com a literatura é na medida em que precede sua inscrição discursiva, tornando possível sua circulação, desde que "opera indiscriminada e anonimamente em todo o tecido social". ${ }^{14}$ Para Gabriele Schwabe, o modelo antropológico desenvolvido na teoria da literatura de Costa Lima se distingue, neste sentido, da teoria do ficcional de Wolfgang Iser, por alocar seu ponto de partida no que a autora chama de "operações miméticas fundamentais" os processos correlatos e necessariamente imbricados de subjetivação e socialização do ser humano. Ou seja, na medida em que a concepção da obra poética do teórico brasileiro remonta a discussão da mímesis ao papel que esta desempenha nos fenômenos de psicogênese e antropogênese

\footnotetext{
${ }^{12}$ LIMA. Escritos de véspera, p.291.

${ }^{13}$ LIMA. Escritos de véspera, p.293.

${ }^{14}$ LIMA. Vida e mímesis, p.211.

${ }^{15}$ SCHWABE. Criando irrealidades: a mímesis como produção de diferença, p.119.
} 
na vida cotidiana, como "mediação que torna a diferença acessível". ${ }^{16}$ Cito a intérprete alemã:

O espaço em que a mímesis atua [...] está intimamente associado ao espaço das representações [...] Devido a sua posição intermediária entre o mundo exterior e o interior, a mímesis representa o real como "forma criada" - uma forma que facilita o processamento do real como diferença. [...] Para se tornar acessível e comunicável dentro da ordem simbólica, essas representações interiores têm de ser moldadas de acordo com símbolos, formas e codificações compartilhados. Para Costa Lima, a mímesis atua como uma dessas forças moldadoras. ${ }^{17}$

Antes de ser um processo de produção do discurso literário e ficcional, a mímesis concerne a uma forma particular de "processamento e elaboração do real", ${ }^{18}$ que tematiza o mundo não em termos de percepção, mas o organiza nos termos do imaginário. Como explicita passagem mais extensa da ex-aluna de Iser:

Há muito que os antropólogos reconhecem na mímesis uma parte integrante da antropogônese. Criando símbolos e sistemas simbólicos que enformam e organizam 'o real' de um modo significativo e coletivamente acessível, a mímesis ocupa uma posição de transição entre o sujeito e seu mundo, entre o interior e o exterior. A mímesis é a força social e cultural que atua na criação e na formação específica de 'espaços interiores', ou seja, espaços nos quais o que é recebido do exterior é processado de acordo com parâmetros tanto culturais como pessoais. Localizada, pois, num 'espaço intermediário', de transição, [...] tomando parte tanto no processamento do mundo exterior quanto na projeção do mundo interior [...] a mímesis transforma o real através de imagens e códigos simbólicos. A função central da mímesis na antropogênese é, portanto, não a imitação, e sim a mediação. ${ }^{19}$

\footnotetext{
${ }^{16}$ SCHWABE. Criando irrealidades: a mimesis como produção de diferença, p.125.

${ }^{17}$ SCHWABE. Criando irrealidades: a mimesis como produção de diferença, p.126.

${ }^{18}$ SCHWABE. Criando irrealidades: a mimesis como produção de diferença, p.126.

${ }^{19}$ SCHWABE. Criando irrealidades: a mimesis como produção de diferença, p.118.
} 
Assim entendida, ela será repensada em sentido mais amplo como um "processo vital", na medida em que sua inoperância comprometeria "a própria existência do sujeito, ao torná-lo incapaz de elaborar a alteridade". ${ }^{20}$ Fato de existência, antes que fenômeno estético, o paradoxo da mímesis decorre de que em sua experiência antropológica fundamental ela põe em cheque a ideia de sujeito uno sobre a qual se estabelece a base de reflexão estética moderna.

Retenham-se, portanto, como limites antropológicos pré-literários da mímesis na teoria de Costa Lima seu enraizamento no impulso préreflexivo de constituição da identidade subjetiva (designado pela noção de mímesis-zero) e sua dependência quanto ao mecanismo impensado de integração numa comunidade de valores (a que se chamará de esquematismo cultural). Sublinhando que sua importância se afirma na medida em que estas duas contraintes precedem a diferenciação discursiva da mímesis como ficção e/ou literatura. Isso, porém, apenas declara seu raio de abrangência.

Donde o que importa destacar: desde que a mímesis literária trava uma relação paradoxal com o que chamamos de verdade, bastando "guardar alguma semelhança com o que uma sociedade [...] tome por verdade $[. .$.$] para sobre esse resto, criar sua diferença - o questionamento$ daquela crença", ${ }^{21}$ o que isso significa senão que, em sua prática mais frequente, a mímesis cumprida no cotidiano contém a raiz mesma daquilo que sua transformação literária torna problemático?

Dito melhor, se a literatura guarda um potencial de questionamento do que uma sociedade toma como verdade, nas demais esferas da vida a mímesis tem como resultado mais frequente o reforço das crenças e valores de seu agente. Fora da arte e antes dela, no espaço dos valores pragmáticos, a mímesis guarda a possibilidade tanto de sua conversão em norma, quanto da sua transgressão de limites - que deixa de ser positiva apenas ao erigir-se em regra avessa. Na medida em que a mímesis não deixa de atuar como veículo de projeção dos valores de seu agente, sempre que se resolve em imitação, anulando o caráter de produção de diferença inerente à repetição contida em seu impulso básico, seu mecanismo assume direção inversa à função pragmática de mediação entre o impensado da Lei e a plasticidade do eu, tornando seus atores

\footnotetext{
${ }^{20}$ Apud SCHWABE. Criando irrealidades: a mimesis como produção de diferença, p.125.

${ }^{21}$ LIMA. Mímesis: desafio ao pensamento, p.63.
} 
incapazes de elaborar a alteridade, seja no sentido amplo (diversidade de crenças, de valores, gênero, sexualidade, ideologia), seja no especializado (diversidade de práticas discursivas).

$\mathrm{O}$ que torna a mímesis uma questão fundamentalmente política, como já sabia seu maior opositor na Grécia antiga. Pois, enquanto reafirmadora de práticas e valores compartilhados por processos de identificação, i.e., admitidos sem reflexão, ainda que possam se tornar retrospectivamente questionáveis, a mímesis pragmática constitui o fenômeno básico de formação de crença, enquanto certeza que não admite contestação. Por isso mesmo, no caso extremo de sua resolução em passividade a mímesis sempre mostra sua face totalitária. Não cogitar dos limites em que sua experiência legitimamente se cumpre, dentro e fora da arte, tornar indiferentes seus espaços, equivale a deixar espaço livre para o avanço de comportamento afins ao neofascismo contemporâneo.

Não é outra a razão da atualidade da obra de Costa Lima: o que ela nos incita é a tarefa de desenvolver a teoria da literatura atual até as dimensões de uma crítica da razão mimética, capaz de redimensionar o lugar do literário. Não apenas enquanto experiência discursiva diferenciada (como performance despragmatizada, que se põe no polo oposto ao privilegiado na pragmática pós-moderna de legitimação do saber), mas como objeto de um controle do imaginário que atua como mecanismo político de defesa dos valores dominantes.

\section{Referências}

LIMA, L. C. Escritos de véspera. Florianópolis: Ed. UFSC, 2011.

LIMA, L. C. Limites da voz (Montaigne, Schlegel, Kafka). Rio de Janeiro: Topbooks, 2005.

LIMA, L. C. Mímesis e modernidade: formas das sombras. São Paulo: Paz e Terra, 2003.

LIMA, L. C. Mímesis: desafio ao pensamento. Rio de Janeiro: Civilização Brasileira, 2000.

LIMA, L. C. Vida e mímesis. Rio de Janeiro: Ed. 34, 1995. 
SCHLEGEL, Friedrich. Introdução à história da literatura europeia (18031804). tradução de Luiz Costa Lima. Anima: História, Teoria e Cultura. Revista do Departamento de Pós-Graduação em História Social da Cultura da PUC-Rio, Rio de Janeiro, ano I, n.1, p. 129-149, 2001.

SCHWABE, Gabriele. Criando irrealidades: a mímesis como produção de diferença. In: GUMBRECHT, H. U.; ROCHA, J. C.; (org.). Máscaras da mímesis: a obra de Luiz Costa Lima. Rio de Janeiro: Record, 1999 1999, p. 115-137.

SOUZA, R. Acízelo (org.). Uma ideia moderna de literatura: textos seminais para os estudos literários (1688-1922). Chapecó: Argos, 2011.

Recebido em: 31 de janeiro de 2019.

Aprovado em: 26 de junho de 2019. 